\title{
Lamellar Ichthyosis: further narrowing, physical and expression mapping of the chromosome 2 candidate locus
}

\author{
L Parmentier ${ }^{1}, C_{\text {C Clepet }}{ }^{1}$, O Boughdene-Stambouli ${ }^{2}, \mathrm{H}$ Lakhdar ${ }^{3}$, C Blanchet-B ardon ${ }^{4}$,

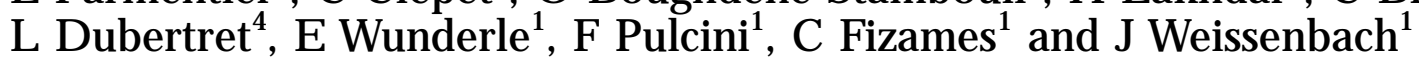

\author{
${ }^{1}$ CNRS URA 1922, G énéthon, E vry, France \\ ${ }^{2}$ Service de D ermatologie, CHU T D jamerni, Tlemcen, A Igeria \\ ${ }^{3}$ Service de D ermatologie, CHU IB N R ochd, Casablanca, M orocco \\ ${ }^{4}$ Institut de Recherche sur la Peau, Paris, France
}

\begin{abstract}
L amellar ichthyosis (LI) is an autosomal recessive genodermatosis which has been shown to be both clinically and genetically heterogeneous. Keratinocyte transglutaminase (or transglutaminase 1: TG M 1) has been demonstrated to be the disease-causing gene in some families, whilst in others, a second unidentified LI gene was mapped to chromosome 2q33-35 (ICR 2B locus). In this study, we present a physical map that encompasses the ICR 2B locus, including the mapping of new microsatellite markers. B ased on this new map, genotyping additional families highly suggests a reduction in size of the candidate interval. The final interval is covered by a single yeast artificial chromosome $(937-\mathrm{H}-3)$ which is $2.2 \mathrm{Mb}$ in length. Fine mapping of potential candidate transcripts was also focused on this region.
\end{abstract}

Keywords: lamellar ichthyosis; I CR 2B; 2q33-35

\section{Introduction}

Lamellar ichthyosis ( $\mathrm{LI}$ ) belongs to the complex group of disorders of cornification. Its prevalence is low $1 / 200000$ to 300000 - and its mode of transmission is usually autosomal recessive (M IM 242300). LI can be life-threatening soon after birth, since the neonate skin is covered by a thick collodion-like membrane, exposing the infant to sepsis and dramatic dehydration. Spontaneous shedding of this membrane gives way to a residual and definitive ichthyosis, presenting as an extensive scaling of the entire body surface. The intensity of the ichthyosis ranges from large brown scales to a fine powdery desquamation. It is also

Correspondence: L Parmentier, Polyclinique de Dermatologie, H opital St. Louis, 75010 Paris, France.

R eceived 15 A pril 1998; revised 15 September 1998; accepted 24 September 1998 variously accompanied by palmoplantar keratoderma, alopecia and erythema. ${ }^{1}$ Some controversial classifications separate the erythrodermic form of LI from the 'pure' $L I,{ }^{2}$ but a lot of patients remain impossible to classify. ${ }^{3}$

Consistent with its variable clinical presentation, LI was demonstrated to be genetically heterogeneous. ${ }^{4}$ Transglutaminase 1 (TGM 1) was the first gene demonstrated to cause LI. ${ }^{4-9} \mathrm{~T}$ his gene directs the construction of the cornified envelope, a protein structure underneath the plasma membrane of keratinocytes which forms during their late-stage terminal differentiation. ${ }^{10}$ H owever, TGM 1 and other known genes involved in cornified envelope construction were firmly excluded in many other LI families (and also in families subclassified as erythrodermic LI).,11,12 For a set of M oroccan families whose phenotypes were compatible with the 'pure' LI definition, we mapped a second 
Table 1 Summary of the clinical features observed in families D to G. Families A, B and C were reported previously (13)

\begin{tabular}{ccccc}
\hline Family & D & E & F & G \\
\hline Collodion baby at birth & + & + & + & + \\
Generalized ichthyosis & + & + & + & + \\
Severe & + & + & + & + \\
M ild & - & - & - & - \\
E rythema & - & - & - & mild to null \\
Palmoplantar keratoderma a & + & + & + & + \\
A lopecia & - & striate & fissurated fissurated \\
\hline
\end{tabular}

disease-causing gene to chromosome $2 .{ }^{13}$ This locus (referred to as IRC2B in the $G$ enome $D$ ata B ase) maps to a $7 \mathrm{cM}$ genomic region which is devoid of any obvious candidate gene. Finally, other LI families were also demonstrated not to be linked to both these loci, ${ }^{13}$ suggesting the existence of at least a third diseasecausing gene.

In the present study, we attempted to refine the ICR2B locus and to map potential candidate transcripts. In the hope of maximising genetic homogeneity, we focused our work on seven LI families sharing the same geographical origin, similar phenotypes, and presenting a potential linkage to chromosome 2q33-35. The physical order of all polymorphic markers of the region was determined in order to allow reliable haplotype construction. O ur results suggested the possibility of a founder effect and, consequently, a substantial refinement of the ICR 2B locus. A transcription map of this region was also established and the fibronectin gene was shown to map to the ICR2B locus.

\section{Patients, Material and Methods}

\section{Patients}

Patients from families A, B, and C were selected as previously reported. ${ }^{13}$ Patients from families $D$ and $E$ were examined at CHU IBN Rochd, Casablanca, Morocco, (HL and CBB). Families $C$ and $E$ originated from the same area of South $M$ orocco. Patients from A lgerian families $F$ and $G$ were examined at CHU T Djamerni, Tlemcen, A lgeria (OBS). $B$ oth families were reported to live in the same village of western A lgeria. The parents of the patients in families $A-F$ are first cousins; individual III-2 of family $G$ was reported to be related to family $F$, but the exact genealogical link could not be established. A II clinical findings are summarised in Table 1.

\section{Yeast Artificial Chromosome Contig}

A Il yeast artificial chromosomes (YACS) tested were selected from contigs WC2.15 and WC2.16 of the Whitehead Institute physical map, ${ }^{14}$ between YA C 846F 4 and 818G 4 (centromeric and telomeric, respectively). Y east clones were obtained from $\mathrm{CEPH}$; cultures and DNA extractions were performed in microtiter plates using standardised protocols. ${ }^{15}$ Sequencetagged sites (STS) tested were obtained from the Whitehead Institute physical map and completed with additional markers from the last G énéthon genetic map. ${ }^{14,16}$ DNA samples were obtained from multiple different cultures of the same YAC and PCR reactions performed at least twice when results were discordant.

\section{Development of New Polymorphic Markers}

Y A C s 914E 7 and 802B 12 were selected since they map to the telomeric portion of the contig. No chimerism was observed by FISH using interA LU-PCR products as probes (data not shown). Both YACs were sized by pulse field gel electrophoresis and gel purified. A fter a total digestion by Sau3A, DNA was cloned in the BamH I site of M $13 \mathrm{mp} 19$. Identification of poly $(A C)$ containing clones and subsequent development of STSs were performed as reported. ${ }^{17}$ These new markers were mapped on the YAC contig and polymorphism was tested on the LI families.

\section{Genotyping and Lodscore Evaluation}

Genotyping was performed using procedures recommended for each marker. ${ }^{17,18}$ For markers D 2S3003, D 2S3004, D 2S3005, D 2S3006 and D 2S3007, the PCR conditions were as published ${ }^{17}$ except that the annealing temperature was $50^{\circ} \mathrm{C}$. $\mathrm{H}$ aplotype construction was done using the most parsimonious phase.

M ultipoint lod scores were calculated using the $\mathrm{HOMOZ}$ program, ${ }^{19}$ restricting the analysis to the most informative markers when necessary. Linkage disequilibrium was tested using the DISE Q package. ${ }^{20}$

\section{EST Mapping}

Expressed sequence tags (EST) from chromosome 2 were selected from the last version of the human genome transcript map. ${ }^{21}$ The multipoint likelihood evaluation was performed using the rhmaxlik subroutine of the RHMAP package. ${ }^{22}$ A ccording to the current output of rhmaxlik, the best locus orders were ranked by maximum likelihood. For each EST position, we used the Deltalog10L value. ${ }^{22}$ which expresses the $\log 10$ likelihood difference from the best order (ie between the maximum likelihood locus order and the proposed order). ESTs displaying a Deltalog $10 \mathrm{~L}$ value ranging from 0 to 3 , that is to say ESTs positioned in the interval D 2S143-D 2S137 with likelihoods within 1000 times that of the best order were considered suitable for fine physical mapping on the YAC contig.

\section{Results}

A unique YAC contig encompassing the previously described LI interval was established (Figure 1). We mapped a total of 68 STSs (including 43 polymorphic microsatellites and $17 \mathrm{ESTs}$ and genes) on 83 YACs. Five of the 43 microsatellites were newly developed for detailed haplotype analysis of the telomeric region (see below). For the establishment of the contig, we retained 
Table 2 Haplotype analysis of the carrier chromosomes in the telolmeric region of the candidate interval. For family G, G indicates the paternal chromosome and G' the maternal chromosome. N umbering of alleles is the same as in Figure 2. The common haplotype between family C and the family G paternal chromosome (which extends to D 2S157) does not appear in totality. Common haplotypes between M oroccan families $\mathrm{C}$ and $\mathrm{E}$ and $\mathrm{A}$ Igerian families $\mathrm{F}$ and $\mathrm{G}$ are shaded. Common alleles for markers D 2S1327 and D2S2394 are also shaded

\begin{tabular}{|c|c|c|c|c|c|c|c|c|}
\hline Families & $A$ & $B$ & $\mathrm{D}$ & $\mathrm{C}$ & $E$ & $F$ & G & $G^{\prime}$ \\
\hline \multicolumn{9}{|l|}{ Centro. } \\
\hline D 2S143 & 4 & 7 & 11 & 6 & 6 & 4 & 6 & 4 \\
\hline D 2S3003 & $(-12)$ & $(-10)$ & 0 & $(+2)$ & $(+2)$ & $(-10)$ & $(+2)$ & $(-10)$ \\
\hline D 2S1345 & 0 & 0 & 0 & $(-3)$ & $(-3)$ & $(-3)$ & $(-3)$ & $(-3)$ \\
\hline D 2S1327 & $(+12)$ & $(+12)$ & $(+12)$ & $(+12)$ & $(+12)$ & $(+12)$ & $(+12)$ & $(+12)$ \\
\hline D 2S128 & 10 & 2 & 1 & 4 & 4 & 4 & 4 & 4 \\
\hline D 2S107 & 0 & 0 & $(-2)$ & $(-2)$ & $(-2)$ & $(+2)$ & $(+2)$ & $(+2)$ \\
\hline D 2S3007 & $(+16)$ & $(+20)$ & $(+20)$ & 0 & 0 & 0 & 0 & 0 \\
\hline D 2S3004 & $(+8)$ & $(+12)$ & $(+8)$ & $(+8)$ & $(+8)$ & $(+8)$ & $(+8)$ & $(+8)$ \\
\hline D 2S2394 & 1 & 1 & 1 & 1 & 1 & 1 & 1 & 1 \\
\hline D 2S2361 & 7 & 4 & 3 & 5 & 7 & 1 & 9 & 1 \\
\hline D 2S137 & 1 & 7 & 5 & 2 & 2 & 2 & 2 & 2 \\
\hline $\begin{array}{c}\text { D } 2 \text { S3005 } \\
\text { Telo. }\end{array}$ & $(-12)$ & 0 & $(-12)$ & $(-14)$ & $(-16)$ & $(+10)$ & $(-12)$ & $(+10)$ \\
\hline
\end{tabular}

only YACs which were positive for at least two STSs. YAC $692 C 5$ was rejected due to ambiguous and nonreproducible results. The YAC clone 961A 4 was found positive for a set of markers of the Whitehead Institute contigs WC2.15 and WC2.16. The final order was consistent with recombination events observed in our families. A reas around markers D2S317 and A F M A 052 Y B 9 were covered by single YA Cs only but were consistent with the overall order of the STSs in this region. Markers D 2S143, D 2S1327, D 2S128, D 2S1345 and D 2S3003 were ordered on the basis of deletions in two Y A Cs (918C 8 and 909 C 10). A deletion in $918 \mathrm{C} 8$ was previously reported for D $2 S 1345$ from the Whitehead Institute map; no deletion in 909C10 has been reported before.

$G$ enotypes of the five Moroccan families with the polymorphic markers are shown in Figure 2 (pedigrees $A$ to $E$ ) and include previous results. ${ }^{13}$ Telomeric and centromeric recombinants are defined by $D 2 S 137$ (family A ) and D 2S325/D 2S2321 (family B). A region of homozygosity, highly suggestive of linkage with ICR 2B was observed in families $D$ and $E$ although their individual lod scores remain below the threshold of 3 . In the proband of family $E$, homozygosity encompasses the region telomeric to AFMB299WB 5 . A common haplotype from D2S143 to D2S2394 is observed in carrier chromosomes of families $\mathrm{C}$ and $\mathrm{E}$ (Table 2 ).

Genotyping of two new A lgerian families provided results in agreement with those for families $A$ to $E$ (Figure 1, pedigrees $F$ and $G$ ). For family $F$, linkage to the ICR 2B locus is supported by a significant lod score ( o od Score $=4.2$, theta $=0$ ). Two centromeric recombinants (individuals IV-1 and IV-3) exclude D 2S2208 and D 2S2242. V isual haplotype analysis of both carrier chromosomes in family $\mathrm{G}$ indicated that:

1) the carrier chromosomes transmitted either by III-2 in family $G$ or by both parents in family $F$ share the same haplotype for markers telomeric to D2S153 (and also for additional markers telomeric to D 2S2382, data not shown);

2) a region of homozygosity was observed between markers D 2S1345 to D 2S2394;

3) the haplotype for the paternal contribution was identical with that found in the Moroccan family E, from D2S1345 to D2S2394 (excepting D 2S107).

Finally, a common allele was observed in carrier chromosomes of all seven families for both markers D 2S1327 and D2S2394 (Table2) but no significant linkage disequilibrium was found ( $P$ value $=0.015$ and 0.122 for D 2S1327 and D 2S2394, respectively). L inkage with the TGM 1 locus on chromosome 14 was excluded in all new families (data not shown).

Since genotyping results strongly suggested that the $\mathrm{LI}$ gene maps in the telomeric region (see D iscussion), we selected ESTs of chromosome 2 from the human genome transcript map and calculated their likelihood 


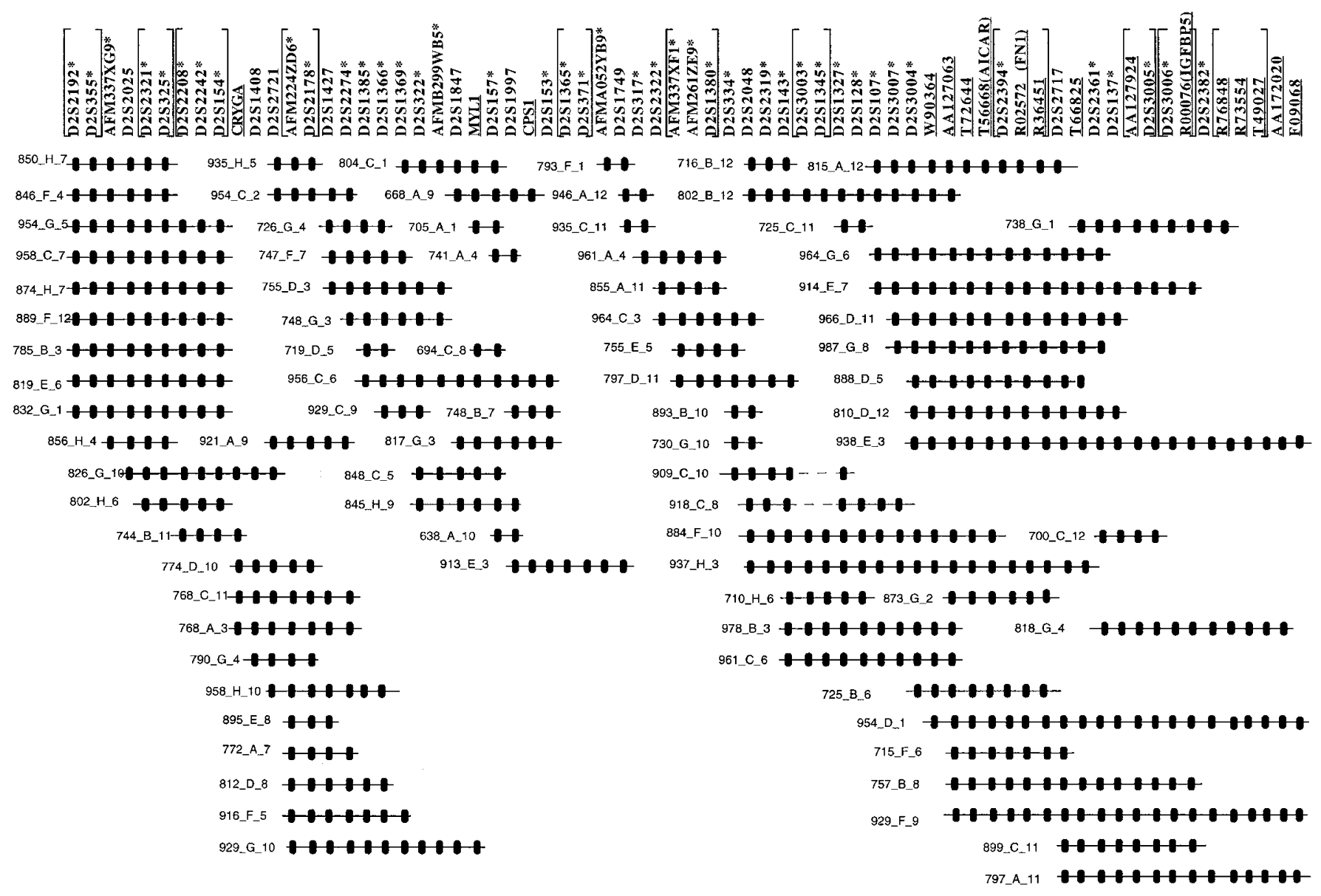

Figure 1 YAC contig encompassing the $L I$ interval on chromosome 2. The YAC names are from the CE PH YAC library database. $M$ icrosatellites are named either by their D-number or their A FM number, and are indicated by an asterisk. ESTs and genes are underlined; they are identified by their G enB ank accession numbers or names (CRY G A for crystallin gamma A, CPS1 for carbamyl phosphate synthetase 1, MYL 1 for human alcali myosin light chain 1). Co-localised markers are indicated by square brackets.

to map between D2S143 and D2S137. Seven ESTs presented the maximum likelihood to map between these last markers, and seven others presented a Deltalog10L value (see Methodology) below 3 for the same interval (Table 3). Finally, seven among them were confirmed to map between D 2S143 and D 2S137 on the YAC contig (Figure 1). Sequence comparison and U NIGE NE cluster ${ }^{21}$ screening revealed that two of them corresponded to known genes (Table 3, clusters

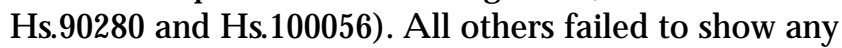
significant homology with known peptides, and notably those with a transglutaminase catalytic domain. A ccording to the expression pattern indicated in the UNIGENE database, only the cluster Hs.100056 was found to be expressed in cultured keratinocytes. This cluster corresponds to the fibronectin CDNA, a gene also expressed in a large variety of tissues.

\section{Discussion}

O ur study was designed to narrow the ICR2B locus, a 7-8cM region of chromosome $2 q 33-35$ that contains a gene responsible for $\mathrm{LI}$. Since LI displays genetic heterogeneity, genetic refinement relies on the study of either large pedigrees or numerous small families with a founder effect. G enotypes of seven North A frican families, using either public or newly developed polymorphic markers, suggested a potential common founder mutation.

Localisation of ICR2B between D2S154 and D 2S2361 is strongly supported by recombination events in families A, B and F, which show individual lod scores above 3. Homozygosity mapping suggests further narrowing of the interval from A FM B 299WB 5 to D 2S137 in nuclear family $E$. Haplotype analysis in other 


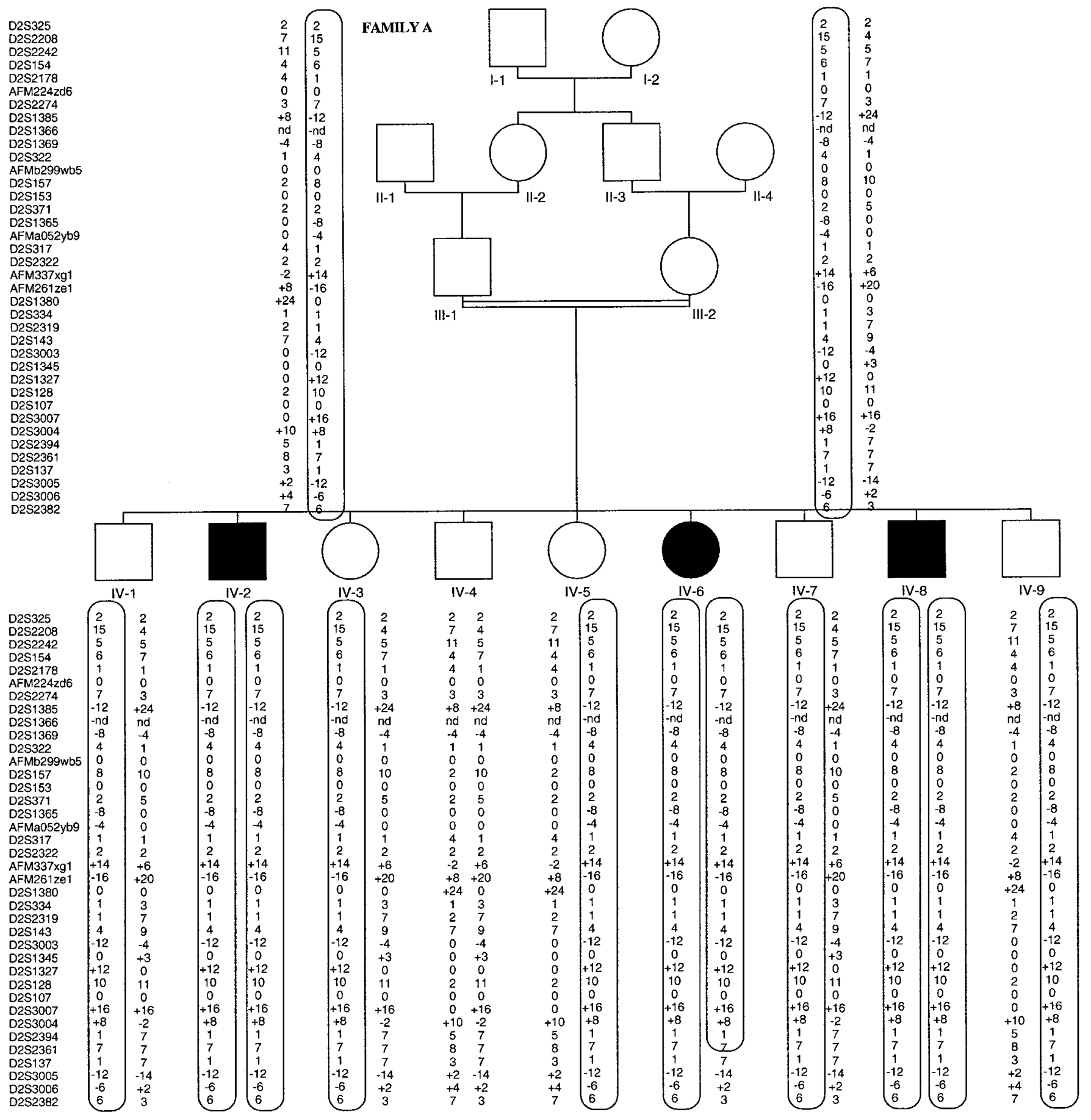

Figure 2 G enotypes of families A to $G$ with the set of markers of chromosome 2. M arkers are indicated by their D -numbers (except for five A FM markers obtained from theWhitehead Institute physical map). Relative positions are consistent with theYAC contig, see Figure 1. R egions of identity by descent in consanguinous families are outlined. N umbering of the alleles of the different markers were consistent with that used in the CEPH database, when available. 0 therwise, they indicate the relative difference in base pairs from the lowest allele of CEPH reference individual 134702. The centromeric part of the ICR 2B locus is not detailed in families D and E.

pedigrees ( $\mathrm{F}$ and $\mathrm{G}$ ) corroborates this result. M oreover, the low prevalence of the disease combined with the very similar geographical origin and clinical presenta- tion of families $F$ and $G$ argues in favour of a common founder event. Since all carrier chromosomes in these two families share the same haplotype between 


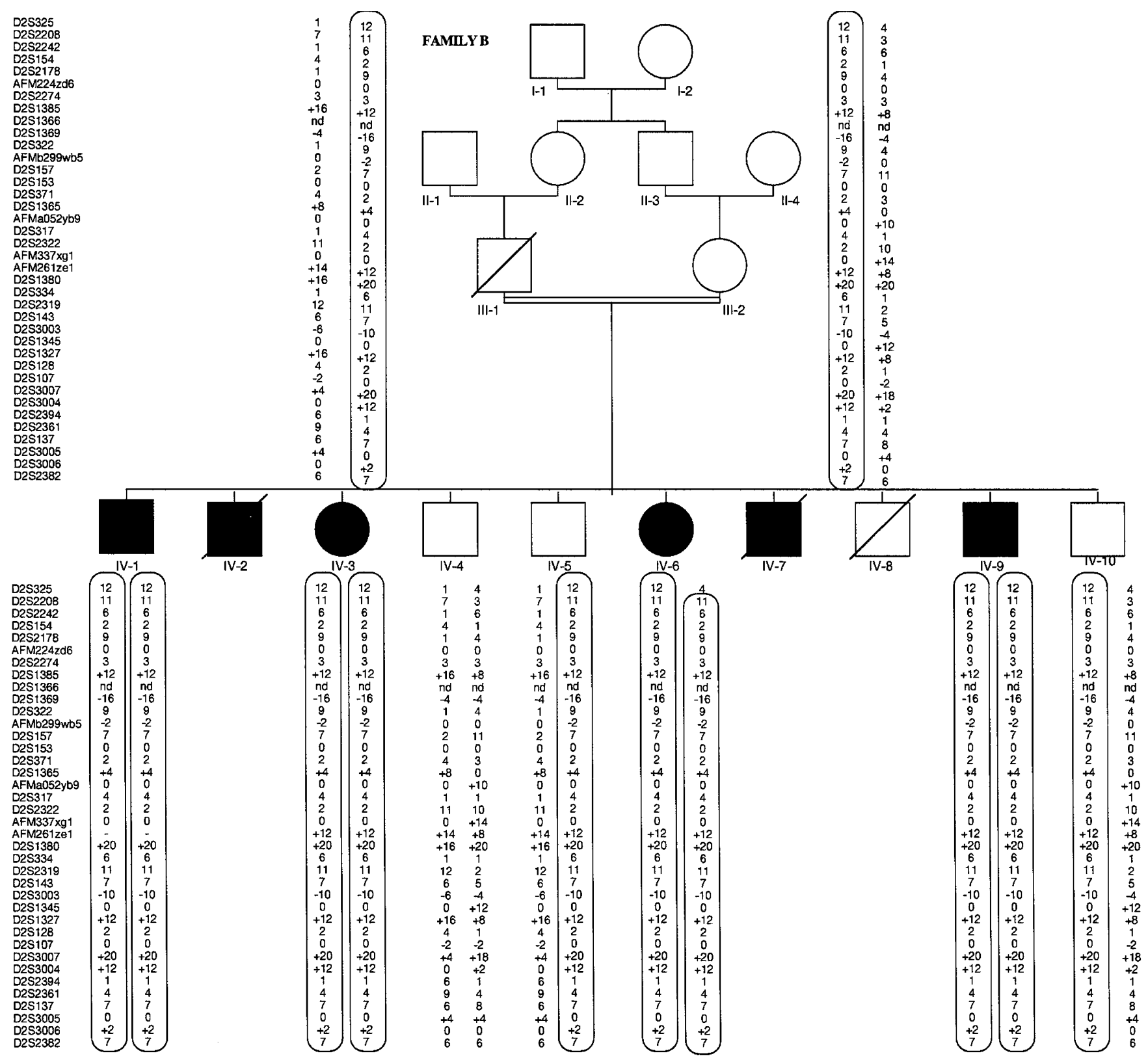

Figure 2b

D 2S1345 and D 2S2394, it is tempting to assign ICR 2B to this interval. Concordant data are observed in families $C$ and $E$, both of which originate from South $M$ orocco (Table 2). This would place the $L I$ gene in a $0 \mathrm{CM}$ interval, covered by a single YAC (937h3) which is $2.2 \mathrm{Mb}$ long, (data not shown). Moreover, for all markers but D 2S107, haplotypes are identical between the carrier chromosomes of the father in family $G$ and both parents in family C (framed by D2S157 and D 2S2394). These data also support a common founder effect between the $\mathrm{A}$ Igerian and $\mathrm{M}$ oroccan families. We did not find a common haplotype in seven families, except for identical alleles for markers D 2S1327 and D 2S2394 (Table 2). Based on these results, it could be hypothesised that a founder haplotype has become unrecognisable due to recombination or mutation events but could still remain in a smaller interval. O ne could also speculate that the LI gene maps close to D 2S1327 or D 2S2394, but either their insufficient informativeness or the small number of chromosomes 

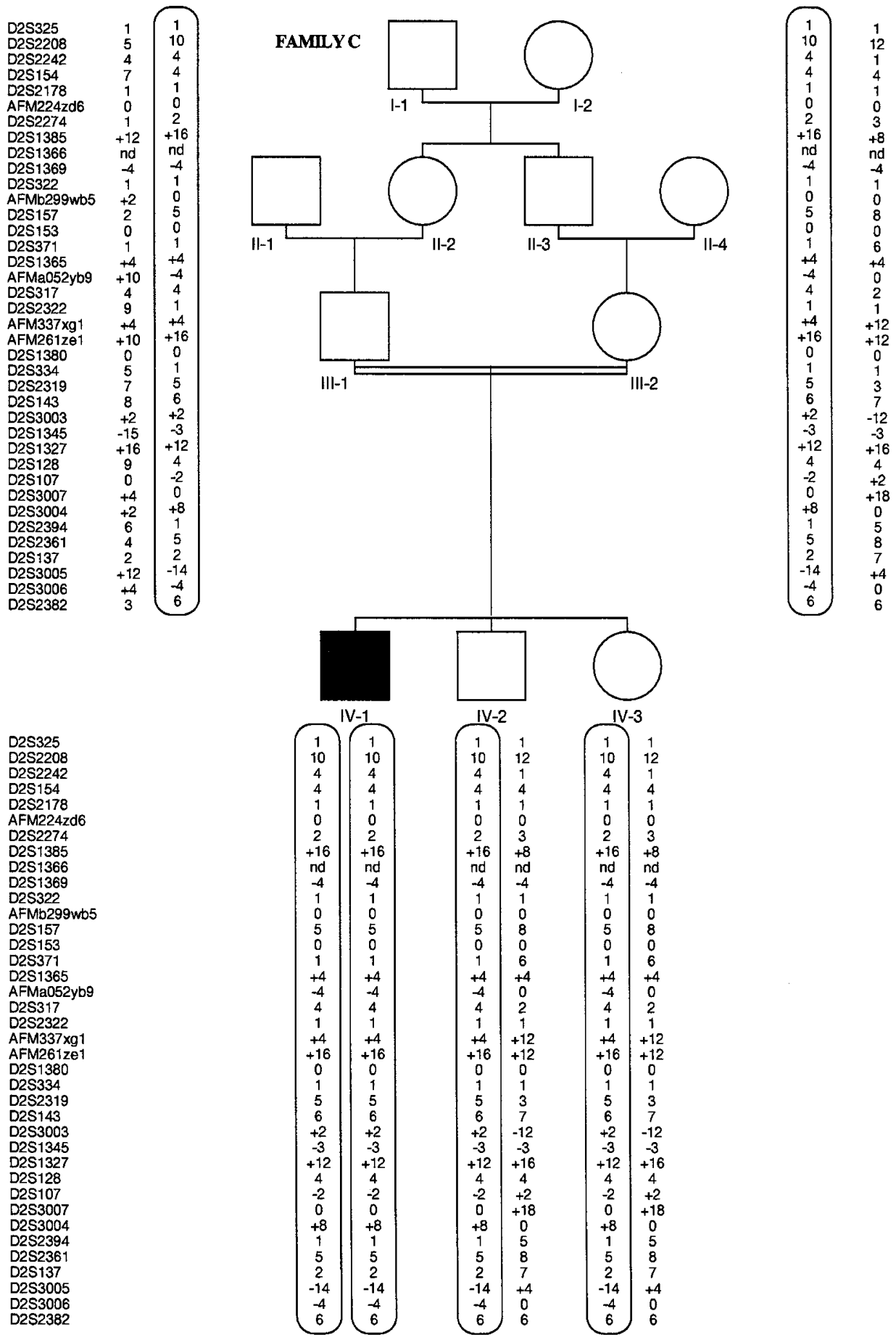

Figure 2c

tested does not permit observation of a statistically significant linkage disequilibrium. Further confirmation requires the comparative analysis of larger populations of both carrier and non-carrier chromosomes.
In an attempt to identify candidate genes in the D 2S1345-D2S2394 critical interval, the human gene map was used. ${ }^{21}$ A mong the seven ESTs for which assignment to the interval was confirmed 

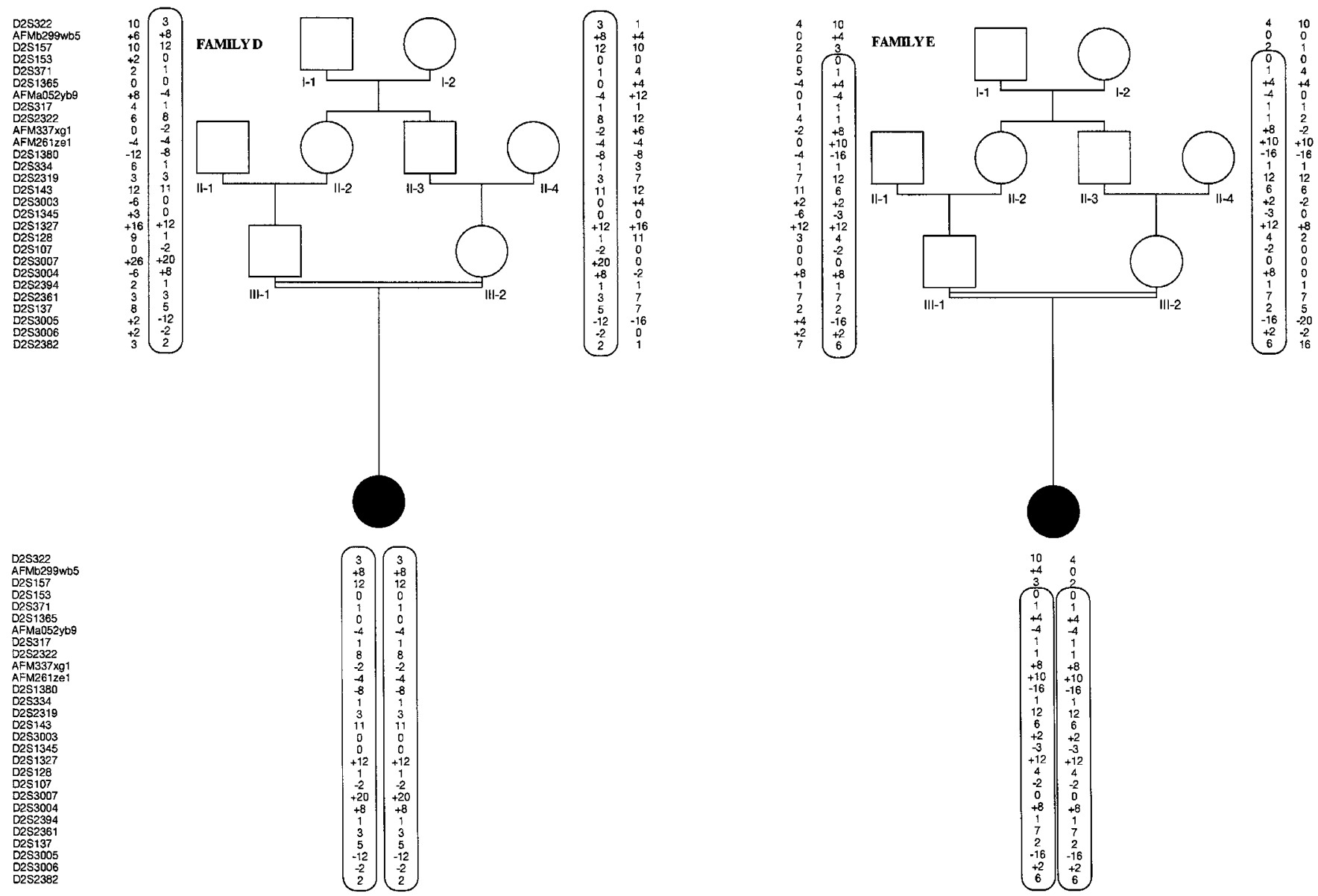

Figure 2d-e

1) none was found to have any homology with a transglutaminase catalytic domain;

2) Hs.90280 corresponds to AICA R, a housekeeping gene involved in purine metabolism; and

3) only H s.100056, which is identical to fibronectin, is known to be expressed in keratinocytes. ${ }^{21}$

Fibronectin is also expressed in other tissues, and is involved in several physiological processes, some of them involving cell adhesion mechanisms. There are several arguments both for and against fibronectin as a candidate gene for $\mathrm{LI}$. O $\mathrm{n}$ the other hand, since some $\mathrm{LI}$ patients present deleterious mutations in TGM 1 , one could speculate that a second LI-causing gene product could directly or indirectly interact with this enzyme. There is as yet no evidence that fibronectin could be a substrate for TGM 1, or that both proteins could be implicated together in the cornification process. Moreover, homozygous fibronectin null mutants are non-viable in the mouse and the embryo

displays dramatic disruption of heart and segment development. ${ }^{23}$ This makes the hypothesis of a nonsense mutation of the gene unlikely. $\mathrm{O} n$ the other hand, it has been shown that fibronectin directs the regulation of keratinocyte differentiation. ${ }^{24,25}$ It also plays a role in inter-keratinocyte adhesion, a process that depends on several specific well characterised regions of the protein. ${ }^{26,27}$ Further screening for mutations in the coding sequence of the gene should therefore focus on these regions, with particular attention to potential missense mutations. In any case, the present study should facilitate the subsequent positional cloning efforts in the identification of the ICR 2B locus gene.

\section{Acknowledgements}

We wish to acknowledge the essential participation of all LI families in the study. We thank D Samson for her support in computer analysis and A Bullot for her contribution in the family collection. We also gratefully acknowledge the stimulating discussions with J Beckman and the constant support 

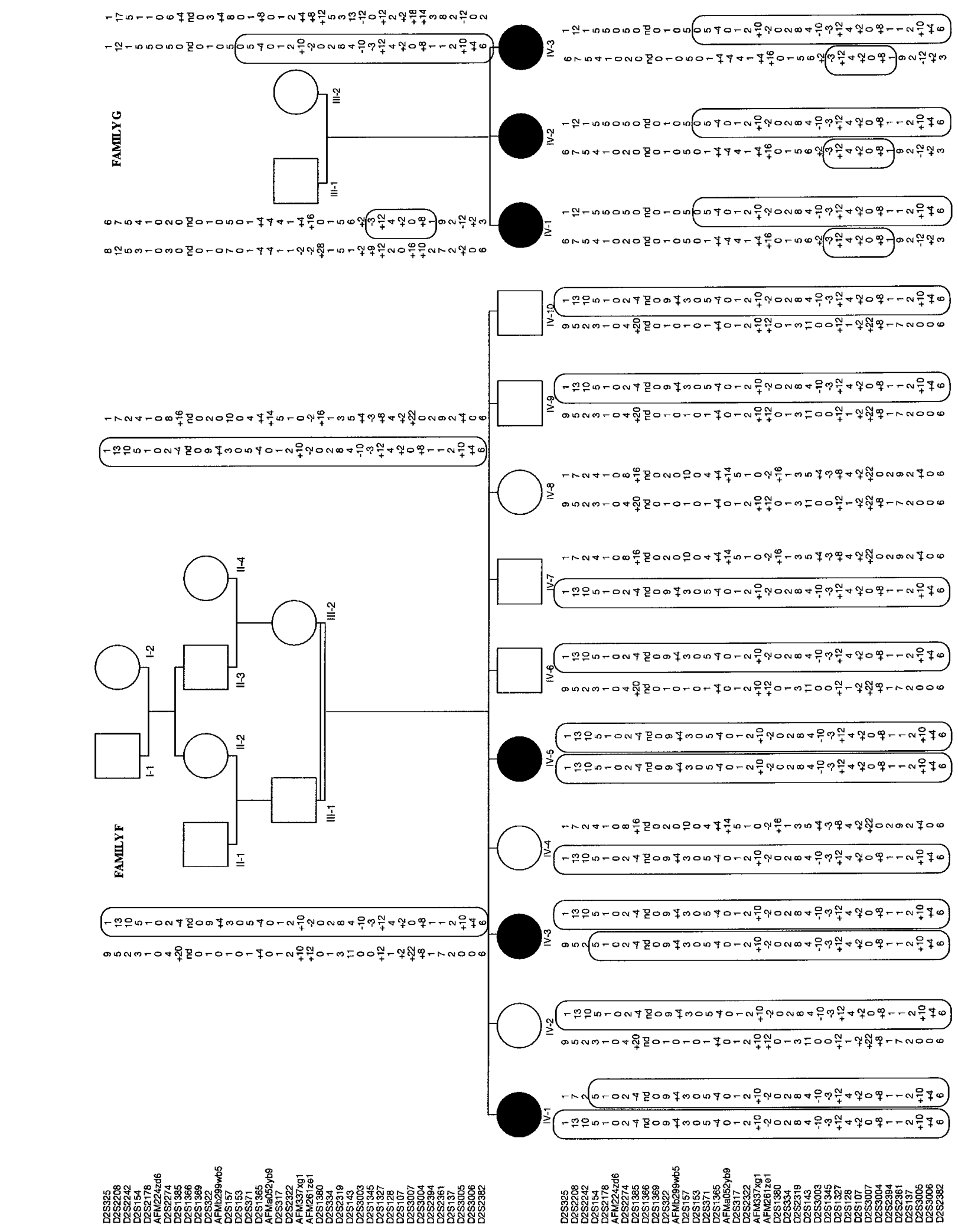

Figure 2f-g 
Table 3 Radiation hybrid mapping of the ESTs from the proposed refined candidate interval. ESTs are identified by their GenBank accession numbers (first column) and their UNIGENE cluster names (second column). For each interval, the Deltalog 1OL value is indicated (see Methods) and is shaded when the position of the EST was confirmed between D2S143 and D2S137 on the physical map

\begin{tabular}{|c|c|c|c|c|c|c|c|}
\hline GENBANK & UNIGENE & D2S355/D2S317 & D2S317/D2S143 & D2S143/D2S137 & D2S137/D2S164 & D2S164/D2S163 & Known gene \\
\hline R 02572 & Hs.100056 & 4.54 & 2.27 & 0 & 3.78 & & Fibronectin \\
\hline A A 127063 & Hs.71063 & 6.45 & 2.27 & 0 & 3.63 & & \\
\hline A A 127924 & Hs.71034 & & 6.18 & 0 & 0.58 & 5.86 & \\
\hline T72644 & Hs.13960 & 6.99 & 3.09 & 0 & 2.68 & & \\
\hline F09068 & no & & 3.45 & 0 & 1.53 & 3.93 & \\
\hline W90364 & Hs.38894 & & 3.13 & 0 & 0.79 & 4.71 & \\
\hline R 36451 & no & 4.81 & 2.23 & 0 & 2.38 & & \\
\hline T66825 & Hs.12950 & & 5.22 & 0.04 & 0 & 3.50 & \\
\hline T56668 & Hs.90280 & & 2.82 & 0.27 & 0 & 0.96 & $\begin{array}{l}\text { Phosphoribosyl-amino-imidazole- } \\
\text { carboxamide formyltransferase }\end{array}$ \\
\hline A A 172020 & no & & & 1.56 & 0 & 2.64 & \\
\hline R 76848 & Hs.79741 & & 6.42 & 1.86 & 0 & 3.36 & \\
\hline R 73554 & Hs.83021 & & & 2.39 & 0 & 0.55 & \\
\hline R 00076 & Hs.18836 & & 7.82 & 2.45 & 0 & 1.81 & $\begin{array}{l}\text { Insulin-like growth factor binding } \\
\text { protein } 5\end{array}$ \\
\hline T49027 & Hs.84981 & & 9.25 & 2.58 & 0 & 1.98 & $\begin{array}{c}\text { ATP-dependent DNA helicase II, } \\
86 \mathrm{KD} \text { subunit }\end{array}$ \\
\hline
\end{tabular}


and interest of R Manaranche. We wish to thank SCure for her critical reading and help in improving the manuscript. This study was entirely supported by the A ssociation Française contre les M yopathies (AFM). LP was also supported by a fellowship from the AFM.

\section{References}

1 Traupe $\mathrm{H}$ : The Ichthyoses. Springer-Verlag: Heidelberg, 1989, pp 111-118.

2 Williams ML, Elias PM: Heterogeneity in autosomal recessive ichthyosis. Clinical and biochemical differentiation of lamellar ichthyosis and nonbullous congenital ichthyosoform erythroderma. Arch Dermatol 1985; 121: 477-488.

3 Bernadt $\mathrm{M}$, Baden $\mathrm{H}$ : R eport of a family with an unusual expression of recessive ichthyosis. R eview of 42 cases. A rch D ermatol 1986; 122: 428-433.

4 Parmentier L, B lanchet-Bardon C, Nguyen S, Prud'homme J-F, D ubertret L, Weissenbach J: A utosomal recessive lamellar ichthyosis: identification of a new mutation in transglutaminase 1 and evidence for genetic heterogeneity. $\mathrm{H}$ um M ol G enet 1995; 4: 1391-1395.

5 Huber M, Rettler I, Bernasconi $K$ et al: $M$ utations of keratinocyte transglutaminase in lamellar ichthyosis. Science 1995; 267: 525-538.

6 R ussell LJ, DiG iovanna JJ et al: M utations in the gene for transglutaminase 1 in autosomal recessive lamellar ichthyosis. Nat G enet 1995; 9: 279-283.

7 Laiho $\mathrm{E}$, I gnatius J, M ikkola $\mathrm{H}$ et al: Transglutaminase 1 mutations in autosomal recessive congenital ichthyosis: private and recurrent mutations in an isolated population. A m J Hum G enet 1997; 61: 529-538.

8 H uber M, Y ee V C, Vikerfors E, L avrijsen A P, Paller A S, $H$ ohl D: Consequences of seven novel mutations on the expression and structure of keratinocyte transglutaminase. J Biol Chem 1997; 272: 21018-21026.

9 Petit E, Huber M, Rochat A et al: Three novel point mutations in the keratinocyte transglutaminase (TGK) gene in lamellar ichthyosis: significance for mutant transcript level, TGK immunodetection and activity. Eur J H um G enet 1997; 5: 218-228.

10 R eichnert $U$, Michel $S$, Schmidt $R$ : In: Darmon $M$, Blumenberg $M$ (eds). M olecular Biology of the Skin - The Keratinocyte. A cademic Press: San Diego, 1993, pp 107-150.

11 Huber M, Rettler I, Bernasconi R, Wyss M, Hohl D: $L$ amellar ichthyosis is genetically heterogeneous - cases with normal keratinocyte transglutaminase. J I nvest Dermatol 1995; 105: 653-654.

12 Bale SJ, Russell LJ, Lee ML, Compton JG, DiG iovanna $\mathrm{J}$ : Congenital recessive ichthyosis unlinked to loci for epidermal transglutaminases. J I nvest D ermatol 1996; 107: 808-811.
13 Parmentier L, Lakhdar H, B lanchet-B ardon C, M archand $S$, D ubertret $L$, Weissenbach J: M apping of a second locus for lamellar ichthyosis to chromosome 2q33-35. H um M ol $G$ enet 1996; 5: 555-559.

14 H udson TJ, Stein LD, G erety SS et al: A n ST S-based map of the human genome. Science 1995; 270: 1945-1954.

15 Chumakov IM, Le Gall I, Billault A et al: Isolation of chromosome 21-specific yeast artificial chromosomes from a total human genome library. Nat Genet 1992; 1: 222-225.

16 D ib C, Fauré S, Fizames $C$ et al: A comprehensive genetic map of the human genome based on 5264 microsatellites. Nature 1996; 380: 152-154.

17 Weissenbach J, Gyapay G, Dib C et al: A secondgeneration linkage map of the human genome. Nature 1992; 359: 794-801.

18 Vignal A, Gyapay G, Hazan J et al: A non-radioactive multiplex procedure for genotyping of microsatellite markers. I : A dolph KW (Ed.). Gene and Chromosome A nalysis - Part A . A cademic Press: San D iego, 1993, vol 1, pp 211-221.

19 Kruglyak L, Daly MJ, Lander ES: Rapid multipoint linkage analysis of recessive traits in nuclear families including homozygosity mapping. A m J H um G enet 1995; 56: 519-527.

20 Terwilliger J: A powerful likelihood method for the analysis of linkage disequilibrium between trait loci and one or more polymorphic marker loci. A m J H um G enet 1995; 56: 777-787.

21 http://www.ncbi.nlm.nih.gov/SCIE N CE 96/

22 Boehnke $M$, Lange $K$, Cox DR: Statistical methods for multipoint radiation hybrid mapping. A m J Hum Genet 1991; 49: 1174-1188.

23 Watt FM, Hodivala $\mathrm{KJ}$ : Cell adhesion. Fibronectin and integrin knockouts come unstuck. Curr Biol 1994; 4: 270-272.

24 A dams JC, Watt FM: C hanges in keratinocyte adhesion during terminal differentiation: reduction in fibronectin binding precedes alpha- 5 beta- 1 integrin loss from the cell surface. Cell 1990; 63: 425-435.

25 A dams J C, Watt FM: Fibronectin inhibits the terminal differentiation of human keratinocytes. Nature 1989; 340 : 307-309.

26 Wilke M S, Skubitz A P, Furcht LT, M acC arthy J B : H uman keratinocytes adhere to two distinct heparin-binding synthetic peptides derived from fibrinonectin. J I nvest Dermatol 1991; 97: 573-579.

27 Wilke M S, Vespa J, Skubitz A P, Furcht LT, M acC arthy J B: $H$ uman keratinocytes adhere to and spread on synthetic peptide $\mathrm{FN}-\mathrm{C} / \mathrm{H}-\mathrm{V}$ derived from fibronectin. J Invest D ermatol 1993; 101: 43-48. 